\title{
ИССЛЕДОВАНИЕ И ПРОФИЛАКТИКА ОСОБЕННОСТЕЙ ПРОЯВЛЕНИЯ БУЛЛИНГА В МЛАДШЕМ ПОДРОСТКОВОМ BO3PACTE
}

\section{Ходюкова Татьяна Александровна}

к.пед.наук., доцент

ФГБОУ ВО «ЗабГУ»

Попова Юлия Владимировна

ФГБОУ ВО «Забайкальский государственный университет», г. Чита

Аннотация: В статье речь пойдёт об особенностях явления «буллинг». Здесь представлены данные исследования, даны конкретные рекомендации по предотвращению ситуации буллинга в образовательном учреждении.

Ключевые слова: Буллинг, агрессивность, конфликт, образовательная среда, подросток, травля, форма поведения, наблюдение, профилактика буллинга.

С каждым годом проблема школьной травли или буллинга становится более актуальной, т.к. именно в подростковом возрасте ведущей деятельностью является межличностное общение со сверстниками. Практически в каждом классе есть дети, которые становятся объектами насмешек, а иногда и открытых издевательств остальных учеников класса. Защитные механизмы и умение сопротивляться сформированы у подростков еще недостаточно. Это может быть связано с тем, что они не обладают достаточно устойчивой Я-концепцией.

Я-концепция - это совокупность представлений человека о самом себе, о том, какими качествами и характеристиками он обладает. Она возникает постепенно, в процессе социального взаимодействия и самопознания, формируется из множества частных образов своего Я и дает человеку ощущение самотождественности и идентичности (Д.И. Фельдштейн, И.С. Кон, Э. Эриксон, Х. Ремшмидт и др.). Недостаточно развитая позитивная Яконцепция, проблемы в становлении адекватной самооценки, особенности стереотипов поведения, принятых в данном обществе, неуверенность в себе, а также, как правило, отсутствие навыков и умений достойного поведения в 
провокационных ситуациях, делают подростков беспомощными. Поэтому большинство из них склонны оценивать себя так, как, по мнению подростка, его оценивают другие, через призму своего соответствия окружающим [1].

Травля периодически поднимается в средствах массовой информации в связи со случаями жестокого проявления в форме физических и психологических травм, особенно в случае попыток или реальных ситуаций насилия. Насилие в школе требует самого пристального внимания, так как именно ситуация в школе во многом определяет дальнейшее развитие подростков и формирование свойств личности. Одной из форм насилия выступает феномен «буллинг».

Английское слово буллинг (bullying, от анг. bully - хулиган, драчун, задира, грубиян, насильник) определяется как притеснение, дискриминация, травля. Одним из первых, кто начал изучать эту проблему, был скандинавский ученый Дэн Олвеус, который провел в 70-х годах исследование явления буллинга среди мальчиков. После этих исследований начались изучения феномена буллинга во все странах[1].

В России исследования В.С. Собкиной, М.М. Смысловой показывают, что регулярному физическому и/или психологическому буллингу подвергались от 0,7 до 4\% московских старшеклассников (опрошено 948 человек), a эпизодическому психологическому буллингу - до $46 \%$ старшеклассников [2].

Д.Олвеус буллинг понимает как особый вид насилия, когда один человек (или группа) физически нападает или угрожает другому человеку (группе), последний из которых слабее и не может себя защитить ни физически, ни морально [1].

И.Н. Кон под буллингом понимает запугивание, физический или психологический террор, направленный на то, чтобы вызвать у другого страх и тем самым подчинить его себе [3].

Д. Лейн определяет явление буллинга как школьная травля и

принимает позицию Роланда, что буллинг - «это длительное физическое или психическое насилие со стороны индивида или группы в отношении индивида, который не способен защитить себя в данной ситуации» [4].

И. Бердышев трактует буллинг как сознательное, продолжительное насилие, не носящее характера самозащиты и исходящее от одного или нескольких человек [4]. 
С.В. Кривцова считает, что буллинг представляет собой один из видов насилия. По ее мнению, буллинг - это агрессия одних детей против других, когда имеют место неравенство сил агрессора и жертвы и, агрессия имеет тенденцию повторяться, при этом ответ жертвы показывает, как сильно она задета происходящим [2].

При изучении литературы складывается стереотипное мнение, что за феноменом буллинга всегда стоит агрессор-буллер и жертва. Проведенное исследование с младшими подростками показало, что среди подростков более всего в практике распространены случаи скрытого буллинга, поэтому не сразу удается выделить агрессора (буллера) и представить явление буллинга как биполярное, агрессор - жертва. Жертва буллинга сама может провоцировать группу подростков, противопоставляя себя другим, или складывается стечение обстоятельств, приводящее к тому, что группа подростков настраивается агрессивно против одноклассника[6].

Актуальность проблемы профилактики буллинга заключается в том, что так и не созданы универсальные способы борьбы с данной проблемой в школах, многие преподаватели не замечают или не хотят замечать травли среди подростков, из-за этого вовремя не оказывается необходимая поддержка и помощь как «жертвам», так и «обидчикам». Буллинг начинает принимать новые формы, все чаще травля происходит в интернете - кибербуллинг. Современным подросткам, являющимися «жертвами» буллинга сложнее избегать ситуаций травли, что негативно сказывается на их психологическом состоянии и может иметь последствия во взрослой жизни.

Цель исследования: теоретическое и эмпирическое выявление особенностей буллинга в младшем подростковом возрасте и разработка рекомендаций по предотвращению ситуации буллинга в образовательном учреждении.

Объект исследования: буллинг как проявление насилия.

Предмет исследования: особенности проявления буллинга в младшем подростковом возрасте.

Гипотеза: Буллинг как особый вид насилия со стороны индивида или группы в отношении индивида, который не способен защитить себя в данной ситуации. Мы считаем, что исследование буллинга и разработка рекомендаций по предотвращению ситуации буллинга, будут способствовать уменьшению проявления насилия в образовательном учреждении.

Задачи исследования: 
1. Рассмотреть понятие буллинга в отечественных и зарубежных исследованиях.

2. Выявить особенности проявления буллинга в младшем подростковом возрасте.

3. Подобрать методы исследования особенностей буллинга в младшем подростковом возрасте.

4. Провести исследование, проанализировать и интерпретировать (представить) полученные данные.

5. Разработать рекомендации по предотвращению ситуации буллинга в образовательном учреждении.

Методология исследования:

Заниматься изучением данной проблемы начали исследователи из европейских стран, такие как Д.Олвеус, Д.Лэйн, Таттуи и многие другие. В России изучением буллинга занимаются И.С.Кон, О.Л. Глазман, И.Бердышев, А.А.Бочавер, К.Д.Хломов.

Методы и методики исследования:

- теоретические (изучение, анализ и обобщение научнотеоретической и учебно-методической литературы по проблеме исследования);

- эмпирические (опросник «Ситуация буллинга в школе» В.Р. Петросянц, наблюдение).

Эмпирическая база исследования:

Исследование на базе Муниципального бюджетного общеобразовательного учреждения «Средняя общеобразовательная школа № 33». В исследовании приняли участие 156 учащихся пятых - седьмых классов.

Теоретическая и практическая значимость: проведен теоретический анализ понятия «буллинг», причины, структура и формы проявления буллинга; рассмотрены типичные черты буллеров и жертв; выявлены особенности проявления буллинга в младшем подростковом возрасте и методы его профилактики. Данные, полученные в результате исследования, могут быть использованы педагогами-психологами, классными руководителями для выявления причин и профилактики буллинга в подростковой среде образовательных организаций.

Эмпирическое исследование проводилось в три этапа: 
Первый этап. На первом этапе нашего исследования мы использовали стандартизированный опросник «Ситуация буллинга в школе» В.Р. Петросянц для выделения классов, где есть ситуация буллинга.

Второй этап заключался в выявлении потенциальных «жертв» и «агрессоров», рассмотрении причин поддержания буллинга. Для этого проводилось наблюдение.

Третий этап включал анализ и интерпретацию полученных данных, разработка рекомендаций по предотвращению ситуации буллинга в образовательных организациях.

Описание методик исследования:

1. Опросник «Ситуация буллинга в школе» В.Р. Петросянц.

Данный опросник позволяет разделить выборку подростков на две группы:

- «жертвы» - ученики, которые представили высокую степень тенденции быть жертвой буллинга и не проявляли агрессивных действий в отношении других учеников;

- «обидчики» - ученики, которые представили себя как участников буллинга частотой несколько раз.

Данный опросник разработан на основе экспертных мнений специалистов центра «Перекресток» и состоит из 6 вопросов, к которым предлагается от одного до восьми ответов с возможностью множественного выбора. Часть предлагаемых ответов характеризует риск буллинга, часть, напротив, свидетельствует о психологической безопасности. Предполагается, что наиболее часто выбираемые в классе варианты ответов соответствуют существующей в классе атмосфере и могут интерпретироваться с точки зрения указания на субъективно переживаемую безопасность или небезопасность и соответствующий риск буллинга.

Интерпретация результатов проводится по 4 шкалам:

1) шкала небезопасности,

2) шкала благополучия,

3) шкала разобщенности,

4) шкала равноправия.

2. Наблюдение.

Наблюдение в психологии - описательный психологический исследовательский метод, заключающийся в целенаправленном и организованном восприятии и регистрации поведения изучаемого объекта. 
При наблюдении явления изучаются непосредственно в тех условиях, в которых они протекают в действительной жизни. Наблюдение применяется там, где вмешательство экспериментатора нарушит процесс взаимодействия человека со средой. Этот метод незаменим в данном случае, ведь нам необходимо получить целостную картину происходящего и отразить поведение индивидов во всей полноте.

В нашем исследовании наблюдение проводилось месяц выборочно, на уроках и переменах с целью выявления потенциальных жертв и агрессоров. При наблюдении фиксировались все агрессивные акты между подростками (вербальные и не вербальные) и заносились в таблицу.

В ходе проведенного нами исследования с использованием опросника «Ситуация буллинга в школе» Петросянц В.Р. было установлено, что в 6-ти (5 «А», 5 «Б», 5 «В», 6 «А», 6 «Б», 6 «В») из 11 -ти классов присутствует буллинг. Наличие буллинга подтверждалось, если в классе агрессивное поведение превышало 30\% (таблица).

Таблица 1

Результаты опросника «Ситуация буллинга в школе»

\begin{tabular}{|c|c|c|c|c|c|c|c|c|}
\hline \multirow[t]{2}{*}{ № ח/П } & \multirow[t]{2}{*}{ Класс } & \multicolumn{3}{|c|}{$\begin{array}{c}\text { Как часто подвергался } \\
\text { буллингу? }\end{array}$} & \multicolumn{2}{|c|}{$\begin{array}{c}\text { Был } \\
\text { свидетелем } \\
\text { буллинга в } \\
\text { классе? }\end{array}$} & \multicolumn{2}{|c|}{$\begin{array}{c}\text { Участвовал в } \\
\text { буллинге } \\
\text { другого } \\
\text { человека? }\end{array}$} \\
\hline & & Никогда & Иногда & Часто & Да & Нет & Да & Нет \\
\hline 1 & $5\langle A »$ & 81,13 & 9,53 & 5,32 & 59,03 & 26,32 & 21,05 & 78,95 \\
\hline 2 & 5 «Б» & 63,21 & 17,72 & 4,65 & 72,44 & 5,56 & 26,78 & 72,22 \\
\hline 3 & $5\langle\mathrm{~B} »$ & 83,9 & 4,32 & 7,8 & 92,98 & 13,04 & 9,7 & 91,3 \\
\hline 4 & $6 \ll A »$ & 71,23 & 6,24 & 6,05 & 99,2 & 2,36 & 15,79 & 84,21 \\
\hline 5 & 6 «Б» & 79,16 & 17,05 & 4,57 & 85,71 & 14,29 & 19.05 & 80,95 \\
\hline 6 & $6\langle\mathrm{~B} »$ & 81,26 & 14,17 & 7,32 & 93,5 & 12,51 & 7,23 & 92,6 \\
\hline
\end{tabular}

Анализируя данные таблицы, мы определили, что в классах присутствует феномен буллинга. От $9 \%$ до $26 \%$ младших подростков проявляли агрессивное поведение по отношению к другому человеку. Агрессивному поведению подвергались от 4\% до 18\% младших подростков из класса. 
Наблюдение за классами осуществлялось месяц выборочно, на уроках и переменах. Критериями наблюдения служили все вербальные (обзывания, дразнение, распространение обидных слухов и т.д.) и физические (пнул, толкнул, ударил и т.д) агрессивные акты между подростками.

Результаты полученных данных по 5-6 классам представлены в таблице ниже.

Таблица 2

\section{Результаты наблюдения 5 «А»}

\begin{tabular}{|c|c|c|c|c|c|c|c|c|c|c|c|c|c|c|c|c|c|c|c|c|c|}
\hline \multicolumn{22}{|c|}{ Агрессивные акты со стороны обидчиков } \\
\hline \multirow{12}{*}{ 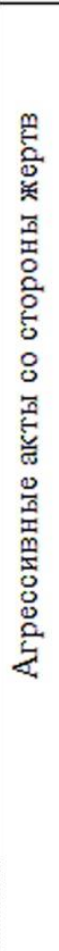 } & Имя & $\Phi$. & P. & M. & A. & B. & Б. & A. & 3. & Д. & C. & M. & K. & A. & C. & A. & Ж. & T. & B. & K. & $\mathrm{H}$. \\
\hline & M. & & + & & & & & & & & & & & & & & & & & & \\
\hline & $\Pi$. & & & & & & & & & & & & & + & & & & & & & \\
\hline & A. & & & & & & & & & & & + & & & & & & & & & \\
\hline & 3. & & & & & + & & & & & & & & & & & & & & & \\
\hline & C. & & & & & & & & & & & & & & & & & & & & \\
\hline & E. & & & & & & & & & & & & & & & & + & & & & \\
\hline & $\mathrm{K}$. & $9+$ & & + & & & $\begin{array}{r}2 \\
+\end{array}$ & $3+$ & $\begin{array}{r}7 \\
+\end{array}$ & & $\begin{array}{r}4 \\
+\end{array}$ & & + & $\begin{array}{r}4 \\
+\end{array}$ & + & $\begin{array}{l}3 \\
+\end{array}$ & & $\begin{array}{r}4 \\
+\end{array}$ & + & $\begin{array}{r}2 \\
+\end{array}$ & $6+$ \\
\hline & C. & & 2 & & & & & & & & & & & & & & & & & & \\
\hline & A. & & & & & & & & & & & & & & & + & & & & & \\
\hline & A. & & & & & & & & & & & & & + & & & & & & & \\
\hline & $\mathrm{K}$. & & & & $2+$ & & & & & & & & & & & & & & 1 & & \\
\hline
\end{tabular}


Таблица 3

\section{Результаты наблюдения 6 «А»}

\begin{tabular}{|c|c|c|c|c|c|c|c|c|c|}
\hline & \multicolumn{9}{|c|}{ Агрессивные акты со стороны обидчиков } \\
\hline \multirow{7}{*}{ 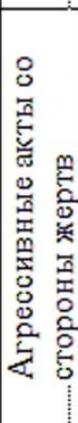 } & Имя & A. & $\Phi$. & $\Gamma$. & A. & B. & A. & Д. & $\Gamma$ \\
\hline & T. & $16+$ & & + & & $4+$ & $2+$ & + & \\
\hline & Д. & & $2+$ & & & & & & \\
\hline & A. & & & & & & & & + \\
\hline & 3. & & & & $2+$ & & & & \\
\hline & A. & & & & & & $3+$ & & \\
\hline & Л. & & & $4+$ & & & & & \\
\hline
\end{tabular}

Таблица 4

\section{Результаты наблюдения 6 «В»}

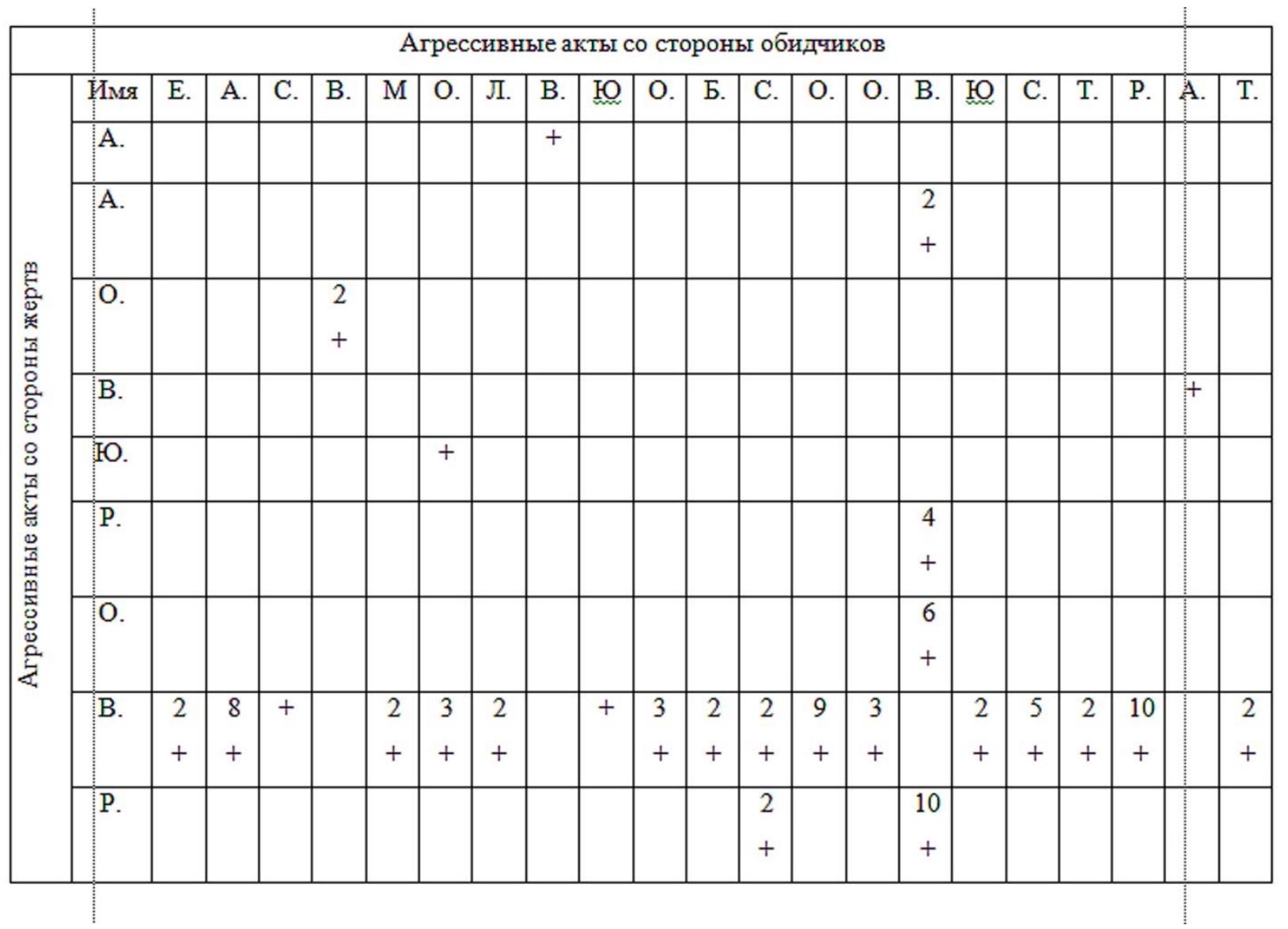

По наибольшему количеству негативных обращений представленных в таблице, мы можем предварительно определить, кто является в классе жертвой, а кто агрессором. Также, можем предположить, из - за кого (жертвы 
или агрессора) поддерживается буллинг в классе. Исходя из данных, представленных в таблицах, можем сделать следующие выводы:

В 5 «А», отвергаемым подростком в классе является Кирилл, так как большое количество негативных воздействий со стороны класса обращено к нему. Наибольшее количество агрессивных актов, обращенных к Кириллу, было со стороны Федора, Захара, Никиты, Анны и Софьи, но также, следует заметить, что из 27 человек в классе, большинство подростков, а именно 15 человек - 60,7 \% класса, проявляли психологическое воздействие по отношению к Кириллу. Предположим, что поддержание буллинга осуществляется жертвой - Кириллом.

В 6 «А» мы можем проследить другую тенденцию проявления буллинга. Исходя из данных таблицы, ярко выраженным агрессором в классе является Артем, а жертвой - Тимур. Исходя из данных таблицы, замечено, что Артем проявлял самое большое количество негативных посылов по отношению к Тимуру. Со стороны Тимура агрессивных актов не прослеживалось. Еще двое подростков в классе проявляли вербальные негативные воздействия на Тимура. Остальные подростки в классе не проявляли агрессивных актов по отношению к Тимуру и к друг другу. Можем предположить, что буллинг поддерживает агрессором.

В 6 «В», исходя из данных наблюдения, представленных в таблице, большинство негативных посылов приходится на Влада, из 25 человек, 17 подростков - 83\% класса, проявляли вербальное негативное воздействие в сторону Влада. Влад также осуществлял агрессивные акты по отношению к своим одноклассникам. Это может свидетельствовать о том, что ситуация буллинга поддерживается жертвой.

Таким образом, исследование показало, что в 5-6 классах есть проявления буллинга на переменах по отношению к конкретному подростку и явление буллинга поддерживается как жертвой, так и буллером. Проведенное исследование свидетельствует о том, что для сплочения коллектива необходима работа как со стороны классного руководителя, так и со стороны педагога-психолога.

Рекомендаций по предотвращению ситуации буллинга в образовательном учреждении:

Основной стратегией предотвращения буллинга в образовательном учреждении является привлечение педагогов, учеников к решению этой 
проблемы, повышение их осведомлѐнности относительно ситуации буллинга в школе[5].

Реализация предполагается на двух этапах.

1 Этап. Работа со школьным персоналом. Педагоги и руководители должны уметь поддержать любые попытки учащихся внести свой собственный вклад в групповые отношения и почувствовать себя нужными. На данном этапе речь о базовой человеческой потребности быть кому-нибудь нужным. Нужно структурировать отношения между учениками класса таким образом, чтобы каждому ребенку хотелось укрепить благополучие своих одноклассников и класса в целом. Это дает им ощущение причастности, включенности в школьную жизнь - мощный фактор личностного развития (повышения самоуважения).

План действий:

1) Сделать ученика своим помощником в решении каких-либо проблем учебного процесса. Для многих властолюбивых, активных учеников - это будет способом канализировать их энергию и удовлетворить их потребность организовывать и руководить чем-то или кем-то «мирным способом».

2) Обращаться как можно чаще к ученикам за помощью в решении дежурных классных проблем.

3) Просить учащихся выражать свое мнение и высказывать свои предпочтения по поводу учебного процесса и других ситуаций.

4) Принимать правила вместе с учениками. Обсуждая это, вы должны прийти к общим правилам, которые будут соблюдаться всеми учениками.

5) Учителям необходимо научиться распознавать проблему, необходимо занять более активную позицию при наблюдении буллинга, не игнорировать эту проблему, так как игнорирование проблемы ведѐт к усилению чувства власти и безнаказанности для «обидчиков» и потери чувства безопасности и доверия у «жертв».

Так же для учителей необходимо проведение мини-лекций, мастерклассов, ролевых игр психологом.

2 этап. Работа с учениками. Целью данного этапа было отведено классным часам, на которых проходила беседа с учениками, в ходе которой объясняли о том, что такое буллинг, о его воздействии и последствиях. А также ученики приводили примеры ситуаций школьной травли, которые тут же разбирались, с помощью проигрывания ролей «жертвы» и обидчиков», тем 
самым ребенок мог посмотреть на ситуацию со стороны, осознать чувства «жертвы», определить способы урегулирования конфликта.

Так же на этом этапе можно использовать:

- беседы психолога с детьми;

- создание кружков, клубов или студий, где могли бы реализовать себя дети с самыми разными склонностями;

- общешкольные квесты, конкурсы типа «Минуты славы», «КВН» «Фабрики звезд», выставки достижений и т. д.;

- мероприятия, способствующие сплочению детей;

- участие в благотворительных акциях «Старость в радость», патронаж домов престарелых, детских интернатов;

- чтение и обсуждение книг, где поднимается проблема травли;

- просмотр и обсуждение кинолент на аналогичную тему;

- написание сочинений, эссе, изложений с элементами сочинения;

- театрализованные постановки;

- психологические тренинги, ролевые игры.

Каждое из этих мероприятий развивает у детей социальную и коммуникативную компетенции, то есть способность уважать мнение других людей и уметь объяснить свою позицию, эффективно сотрудничать в коллективе.

После применения практических рекомендаций, на примере 5 - го «А» класса, ситуация буллинга заметно уменьшилась, этому свидетельствует повторно проведенное в конце выполненных рекомендации наблюдение, результаты которого показали: Кирилла, который являлся жертвой в классе, отметили, как низко статусного подростка в классе, всего лишь 2 учащихся в классе, а это 8\% класса. Мы видим, что подростки изменили отношение к Кириллу.

Таким образом, сформулированная гипотеза нашла своѐ подтверждение в процессе исследования. Можно констатировать, что цель исследования достигнута, задачи реализованы. Актуальность данной работы чрезвычайно высока, так как систематических исследований с выходом на эффективность практики преодоления случаев школьного буллинга в России недостаточно. Это связано с тем, что буллинг является скрытым процессом, и до недавнего времени службы социальной поддержки в стране были мало распространены, жертвам буллинга некуда было обратиться за помощью. Для того, чтобы 
можно было помочь жертве буллинга и предотвратить агрессивность поведения в группе, необходимо изучить ситуацию и воздействовать на всю структуру в целом, действия должны иметь последовательный характер.

\section{Список литературы}

1. Аверьянов А.И. Буллинг как вызов современной школе // Педагогика, психология и социология. - 2013. - № 18. - С. 45-50.

2. Баева И.А. Школьная травля (буллинг) в образовательной среде [Электронный ресурс]/ Баева И.А., Петросянц В.Р. - Режим доступа: http:// nrcnn.ru/lang/activity/study.html?id=149

3. Кон И. С. Что такое буллинг и как с ним бороться? // «Семья и школа». - 2006. - № 11. - С.15-18. 19. Кон И.С. Мальчик - отец мужчины. М.: Время. - 2009. - 704 c.

4. Буллинг - травля детей. Что делать? // Санкт-Петербургское государственное учреждение социальной помощи семьям и детям "Региональный центр "Семья": [сайт]. - Спб., [1995 - 2012]. - Режим доступа: http://homekid.ru/bullying/bullyingPart1.html

5. Буллинг - травля детей. Что делать? // Санкт-Петербургское государственное учреждение социальной помощи семьям и детям "Региональный центр "Семья": [сайт]. - Спб., [1995 - 2012]. - Режим доступа: http://homekid.ru/bullying/bullyingPart1.html

6. Бердышев И.С., Нечаев М.Г. Медико-психологические последствия жестокого обращения в детской среде. Вопросы диагностики и профилактики: Практическое пособие для врачей и социальных работников / СанктПетербургское государственное учреждение социальной помощи семьям и детям «Региональный цент «Семья». 2005. [Электронный ресурс]. URL: http://old.homekid.ru/bullying/contens.html

(C) Т.А. Ходюкова, Ю.В. Попова, 2020 